\title{
The 'digital transnational solidarity' and protection of health: Commentary to Principle no. 7 of the Rome Declaration
}

\author{
Roberto Cippitani \\ Centre of Research 'Rights and Science', Department of Medicine and Surgery, University of Perugia, \\ Building A - Piazzale L. Severi, Sant'Andrea delle Fratte, Perugia, Italy \\ E-mail: roberto.cippitani@unipg.it
}

Received 8 December 2021

Accepted 29 December 2021

\begin{abstract}
.
BACKGROUND: Point 7 of the Rome Declaration is aimed at improving data sharing and technological and knowledge transfer as instruments to implement health policies.

OBJECTIVE: The objective of the current paper is to understand if the legal framework (especially at a transnational level) may actually help to achieve the objectives laid down by Principle 7 or if some interpretative or legislative actions will be necessary. METHODS: The paper analyses the legal sources at international and EU levels.

RESULTS: The applicable rules are based on the idea that the information and material are forms of 'property' of the individuals or of the states (i.e., the sovereign). According to the traditional idea of property, the owner has a sort of absolute power over the res and is entitled to exclude others from any rights over the thing. The 'property paradigm' may be useful to protect some relevant interests, but it can also affect collective interests, such as those concerning health during the COVID-19 pandemic. CONCLUSIONS: In order to build a global system for the exchange of data and materials as provided for by Principle 7 of the Rome Declaration, a new legal approach should be elaborated which takes into consideration the international corpus of fundamental rights, including research freedom, the right to health and the principle of transnational 'digital' solidarity.
\end{abstract}

Keywords: Data, information, open science, freedom of research, right to health

\section{Background}

Principle no. 7 of the Rome Declaration is aimed at improving data sharing, capacity building and technological and knowledge transfer as instruments to implement public health policies.

In addition to fighting against the COVID-19 health crisis, the Rome Declaration points out the relevance of the use of other biological materials, such as those of animals (see Principle no. 10 of the Declaration).

The availability and circulation of data, information, knowledge and materials are essential in all fields of research [1], but they are particularly important in a period in which it is necessary to tackle a global phenomenon like the COVID-19 pandemic. 
Among today's most important research tools are datasets, collections of materials (see, e.g., Article 2 of the International Treaty on Plant Genetic Resources for Food and Agriculture of FAO of November 2001 and Article 2 of the Convention on Biological Diversity approved by the United Nations in 1992, hereinafter referred to as CBD) and, in particular, biobanks, that is, 'any collection of biological materials, whether the source be human, plant, or animal, fungi, bacteria, microorganisms or other living families, as well as bioinformatic data on such organic materials' [2]. The collections of materials are the fundamental 'infrastructures' for scientific research, as underlined by the documents of the international organisations (see OECD, best practice guidelines for biological resource centres, 2007).

The main issue addressed by the current paper is to understand if the legal framework (especially at a transnational level) may actually help to achieve the objectives laid down by Principle 7 or if some interpretative or legislative actions will be necessary.

\section{Limitations on the circulation of data}

An analysis of the current legislation seems to indicate several legal constraints on the circulation of data (information, knowledge and material).

This is the case in the discipline of 'intellectual property rights' which attributes to authors of works or inventions the exclusive right to exploit those works or inventions (see the definitions provided by the Paris Convention for the Protection of Industrial Property of 20 March 1883, as last amended on 28 September 1979, and the Berne Convention for the Protection of Literary and Artistic Works of 9 September 1886, last amended on 28 September 1979).

Other important norms lead to a restriction on the sharing of information, such as legislation on the protection of personal data (see in European Union Law, Regulation (EU) no. 2016/679, hereinafter referred to as "GDPR"), the discipline for clinical trials (see, for example, Regulation (EU) no. 536/2014), and the use of genetic information (see Article 2 of the International Declaration on Human Genetic Data adopted by UNESCO in 2003). Such norms put information under the control of the 'data subject' who is entitled to give his/her consent for all uses of personal data [3].

International Treaties concerning biodiversity may also prevent the sharing of information and biological materials, that is, genetic resources from plants and animals. This is the approach of the CBD (see Article 15, para. 1) as well as of the International Treaty on Plant Genetic Resources for Food and Agriculture (ITPGRFA, see Article 10.1) and of the Convention on Access to genetic resources and the fair and equitable sharing of benefits arising from their use of the Convention on Biological Diversity of 2014 (hereinafter referred to as the Nagoya Protocol; see within EU law, Regulation no. 514/2014 of the European Parliament and of the Council of 16 April 2014).

In particular, Article 15, para. 1, CBD states that 'Recognizing the sovereign rights of States over their natural resources, the authority to determine access to genetic resources rests with the national governments and is subject to national legislation'.

In addition, the preamble to the United Nations Framework Convention on Climate Change recalled that the 'States have, in accordance with the Charter of the United Nations and the principles of international law, the sovereign right to exploit their own resources pursuant to their own environmental and developmental policies' and reaffirmed 'the principle of sovereignty' of States in international cooperation to address climate change. 
The assertion of sovereignty is consistent with the approach of international law governing relations between autonomous and independent states [4] that have the ultimate power to actually implement the transnational rules [5].

These rules are based on the idea that information ${ }^{1}$ and material are forms of 'property' held by individuals [6] or by the states ${ }^{2}$, depending on the situation. According to the traditional idea of property, the owner has a sort of absolute power over the res and is entitled to exclude the rights of third parties.

This property scheme may be useful to protect some relevant interests. The discipline on privacy tries to protect the individuals from the enormous risks derived from the use of personal data. In the case of natural genetic resources, the affirmation of state sovereignty has been a response to the depredation of natural resources to the detriment of the developing countries. However, the 'proprietary paradigm' may lead to effects on important interests that are different from those of the owners.

For example, the consent provided by the discipline governing personal data derives from an individualistic logic ${ }^{3}$ which, if applied in an absolute way, can prevent other individual or collective interests from being satisfied (e.g., the use of personal data to protect the health of other individuals). In the case of genetic resources, the national sovereignty ensured by international law may be in conflict with other legitimate purposes, such as the protection of the rights of indigenous communities present in particular territories. Those rights are also recognised by international instruments (see, for example, Article 2 of the Nagoya Protocol) [7] but it is not clear how they may be protected from actions of the states.

In addition, sovereignty fails when it is necessary to safeguard the environment, which does not belong to a specific state but is a common asset of humankind ${ }^{4}$.

\section{Proprietary paradigm vs. protection of health and scientific research}

Whether in the case of personal data or in the case of natural resources, the proprietary paradigm may represent an obstacle to carrying out activities in the common interest, such as scientific research or the protection of public health.

There are rules that recognise those interests in the processing and circulation of data and materials. For example, research on genetic make-up and/or biochemical composition of genetic resources is considered particularly relevant in the Nagoya Protocol. Article 8 provides that each state shall 'create conditions to promote and encourage research which contributes to the conservation and sustainable use of biological diversity, particularly in developing countries, including through simplified measures on access for noncommercial research purposes, taking into account the need to address a change of intent for such research' (see also recitals 6, 18, 27 and 28 and Article 13 of Regulation (EU) No 511/2014).

\footnotetext{
${ }^{1}$ The famous work by Samuel Warren and Louis Brandeis, 'The Right to Privacy' published in the Harvard Law Review in 1890 , constructs the notion of 'privacy' as the right of the individual to exclude others from invading his/her personal sphere. In practice, privacy was born as an extension of the logic of property (originating in Roman law) from the physical to the 'spiritual' sphere.

${ }^{2}$ Sovereignty was considered as a sort of 'property' by Grotius in De iure belli ac pacis.

${ }^{3}$ Article 29 Data Protection Working Party, Working Document on Genetic Data, Adopted on 17 March 2004, p. 8.

${ }^{4}$ See the case of the President of Brazil, Bolsonaro, who affirmed national sovereignty over the Amazon forest in order to exclude any intervention of the international community. See his speech at the General Assembly of the United Nations on 24 September 2019. https://www.reuters.com/article/us-un-assembly-brazil/bolsonaro-attacks-lying-media-on-amazon-firesdemands-respect-for-brazils-sovereignty-idUSKBN1W91WV.
} 
However, the states have the last word in determining the measures which would allow scientists to use genetic resources. In particular, each legal system gives its interpretation of concepts such as research and non-commercial research (according to EU law, for example, see the definitions provided by the European Commission, Communication, Framework for state aid for research and development and innovation, C(2014) 3282 of 21 May 2014). This can constitute an obstacle to the circulation of materials and information in a field such as science in which national interests are often considered to take precedence over benefits to the international community.

Article 7 of the Agreement on Trade-Related Aspects of Intellectual Property Rights (as amended by the 2005 Protocol Amending the TRIPS Agreement) provides that 'The protection and enforcement of intellectual property rights should contribute to the promotion of technological innovation and to the transfer and dissemination of technology, to the mutual advantage of producers and users of technological knowledge and in a manner conducive to social and economic welfare, and to a balance of rights and obligations'.

Any decision is subject to the discretional power of the states as provided by Article 8 of the same agreement. As a matter of fact, the Member States 'may' 'adopt measures necessary to protect public health and nutrition, and to promote the public interest in sectors of vital importance to their socioeconomic and technological development' and to 'prevent the abuse of intellectual property rights by right holders or the resort to practices which unreasonably restrain trade or adversely affect the international transfer of technology'.

Although the legal sources concerning the circulation of information, especially the international instruments, still depend on the property paradigm, it is possible to observe some paradigm shifts which may allow a different interpretation of the present rules and other future regulations.

\section{Open science and freedom of knowledge within EU law}

A first interesting process aims to 'open' the science, that is, move from the mainstream approach based on the protection of information to a collaborative system to share scientific data. This would take advantage of possibilities within the information and communication technologies.

A first popular application of the open approach to research was the international Human Genome Project started in the early 1990s which allowed the decoding of the human genome in a period of less than 15 years and the worldwide sharing of the knowledge. In addition, many of the research initiatives carried out to fight the COVID-19 pandemic represent examples of open science (see, for example, the European COVID-19 Data Platform, available at https://www.covid19dataportal.org/).

In brief, open science may be defined as an approach to scientific activities based on open and cooperative work, as well as on tools and the diffusion of knowledge (see Article 2, n. 5, Regulation (EU) 2021/695 of the European Parliament and of the Council of 28 April 2021 establishing the programme Horizon Europe) [8].

This openness may be useful for scientific research and also innovation, that is, the transformation of knowledge into economic and social development [9].

In addition, Open Science has an impact on the entire research cycle, from the inception of research to its publication, and on how this cycle is organized' (see the communication of the European Commission, 'Open innovation, open science, open to the world.A vision for Europe', 2016).

Within the EU law, the objective to open science and innovation has implied the adoption of the legislation on the free circulation (see the Regulation (EU) 2018/1807 of the European Parliament and of 
the Council of 14 November 2018 on a framework for the free flow of non-personal data in the European Union) and re-use of data (see the Directive (EU) 2019/1024 of the European Parliament and of the Council of 20 June 2019 on open data and the re-use of public sector information), as well as the creation of specific infrastructures focused on data (see European Commission, European Cloud Initiative-Building a competitive data and knowledge economy in Europe, COM/2016/0178 final).

Furthermore, the legal base of the EU Programmes, in particular the current Horizon Europe, provide the obligation for the beneficiaries to publish in open access and to deposit the data in repositories freely accessible by the scientific community and by the public (Article 14, para. 1, Regulation (EU) 2021/695 of the European Parliament and of the Council of 28 April 2021 establishing Horizon Europe).

Those legal sources constitute the implementation of the objective of the overall governance of data (see the Proposal for a Regulation of the European Parliament and of the Council on European Data Governance [Data Governance Act] COM/2020/767), especially to build a European health data space (see recitals no. 3 and 19 of the Proposal of Regulation; see Annexes to the Communication of the European Commission, Commission Work Programme 2021, [COM(2020) 690 final]) and to stimulate research and innovation (see recital no. 20 of the Data Governance Act).

According to EU law, the circulation of data for activities in the public interest, such as health and research, is one of the main dimensions of the European Research Area in which researchers, technology and, moreover, knowledge may circulate freely (see Article 179, para 1, Treaty on Functioning of the European Union [TFEU]) [10].

The documents of the European institutions affirm on the basis of Article 179 TFEU that the Union and the Member States must guarantee and promote 'freedom of knowledge', which is considered to be the fifth freedom granted by the Treaties of the European Union ${ }^{5}$ in conjunction with the free movement of persons, goods, services and capital. Furthermore, freedom of research is considered to be a fundamental right (Article 13 Charter of Fundamental Rights of the European Union) [11].

In order to build a true European Research Area (Communication of the European Commission, 'Towards a European Research Area', COM [2000] 6 final, 18 January 2000), the Union has to encourage the free circulation of research and cooperation between undertakings, research centres and universities and also remove obstacles to this circulation and cooperation.

\section{Property and human rights}

The present legal sources concerning data, based on the proprietary logic, should take into consideration that in the last decades the 'terrible individual right' itself (as Stefano Rodotà has called property) [12] has changed profoundly.

Within national constitutions and international instruments, property is no longer an absolute power over a material thing. This is because the objects of rights are often immaterial and, above all, because the right to property is recognised from the perspective of its social function (see, for example, Article 42 of the Italian Constitution), that is, as a tool to implement interests that go beyond those of the owner.

In addition, property itself is considered as a fundamental right (see, for example, Article 41 of the Italian Constitution; Article 1 of the Additional Protocol to the European Convention of Human Rights). This evolution of the right of property is clearly shown in the case law of the regional Courts.

\footnotetext{
${ }^{5}$ See the communication of the European Commission, 'Better careers and more mobility: A European partnership for researchers', 23 May 2008, COM(2008) 317 final.
} 
In this sense, the European Court of Human Rights protects all forms of property recognised by law, regardless of whether it refers to a material good, and often uses property to protect non-patrimonial interests. For example, in the judgement of Maurice and Daon of 2005, the Court of Strasbourg referred to property in order to declare a contract under Article 1 of the Additional Protocol as above French law no. 2002-203, also known as 'loi anti-Perruche', which limited medical liability in the event of a malformation of the foetus as well as for controversies raised before the law entered into force ${ }^{6}$.

The traditional idea of property, based on the exclusion of others from the enjoyment of material goods, is no longer adequate to understand and regulate the phenomena of the present knowledge-based society [13] which depends on the access to information [14]. Furthermore, concepts such as sovereignty within the so-called global constitutionalism [15] have changed in meaning. The exercise and protection of fundamental rights is the present justification for political power [16]. As property is the fundamental right and instrument for implementing other fundamental rights, it must be applied consistently within the constitutional systems and within international human rights law.

The link between property and human rights has been confirmed in recent years in the theory of commons [17], which seeks to protect some goods which, regardless of being the object of rights of individuals, must be able to be used by all humanity, such as water, air, and, in general, the environment. Access to and enjoyment of such property is considered as a fundamental right.

Therefore, information necessary to protect collective and individual health can be considered as a common good, since it is associated with interests that are not those of a particular state or individual.

\section{The principle of solidarity}

The sharing of data for collective interests, such as research and health, is also expected to implement the principle of solidarity. In the context of a legal system built on the idea of fundamental rights, the rights to information can no longer be considered only from the individual and selfish point of view but also as an expression of the duty of solidarity [18] provided by the constitutions (see Article 2 of the Italian Constitution of 1948, for example, which recognises and guarantees the inviolable rights of the individual which must be exercised with respect for the 'non-derogable duty' of political, economic and social solidarity. See also, for example, Article 10, para. 2, Constitution of Spain; the French Constitution of 1946, referred to in the Preamble of the Constitution of the Fifth Republic).

Solidarity in its modern meaning [19] may be defined as the duty to protect the interests of other persons, in particular, vulnerable people. Such a principle is applicable in all social and legal relationships, both vertical (between public authorities and citizens) and horizontal (between individuals, e.g., family and contractual relations), including with respect to property.

To explain the present importance of solidarity, scholars refer to its 'pervasive character [20]' and consider it a "moral value, assumed as a specific political value ... in a legal value, through the legal

\footnotetext{
${ }^{6}$ Another interesting case is the right to property (see Article 21 of the American Convention on Human Rights) developed by the Inter-American Court of Human Rights (see, for example, in the Yakye Axa Indigenous Community v. Paraguay case; Corte IDH, judg. 17 June 2005, Comunidad indígena Yakye Axa/Paraguay, Series C No. 25). According to that case law, the Court affirms that 'property' - in this specific case the right of indigenous peoples over 'ancestral' territories-is the means for the protection of the human rights of members of the indigenous community. As the Court recognizes, it is 'a land right different from the general concept of private property law'. In contrast, property, as a human right, is a set of aspects of material elements and of intangible components, political, symbolic, cultural.
} 
system [21]'. Solidarity has also been the principle behind the European integration process since the Declaration of Schuman of 9 May 1950 [22].

European solidarity is today one of the founding principles of the European Union (see Article 2 of the Treaty of the European Union and the Charter of Fundamental Rights), governing the actions of the Institutions (see, for example, the policy of regional cohesion under Article $174 \mathrm{ff}$. of Treaty on Functioning of the European Union) and the relationships between Member States and with other counties in the world (see Article 3 of Treaty on European Union). In addition, solidarity allow actions in the case of emergencies (see Article 122 TFEU), as is occurring in the present pandemic in which states face the health and economic consequences of the crisis, both inside and outside the EU [23].

Solidarity is also the principle supporting regional integration on other continents, as in the case of Latin America (see, for example, the Constitutive Treaty of the Union of South American Nations (UNASUR), signed in Brasilia on 23 May 2008 by Argentina, Bolivia, Brazil, Colombia, Chile, Ecuador, Guyana, Paraguay, Peru, Suriname, Uruguay and Venezuela).

Solidarity is also central to international cooperation [24] due to the interdependence in multilateral relations [25] and is replacing the pragmatic bilateralism and utilitarianism that has traditionally characterised international relationships [26]. As underlined in the international literature, the principle of solidarity has led to the transition to a value-based legal order which affects many areas of international law [27]. Solidarity, therefore, has become the constitutive element in international cooperation in the framework of humanitarian law and helps to affirm human rights [28].

In particular, the principle of solidarity should inspire the coordinated actions of states and the international organisations to ensure individual and collective health, especially in the present emergency [29]. The pandemic is a test case for implementing solidarity in terms of global collaboration to accelerate vaccine production, develop concurrent vaccination campaigns and ensure equitable access to medical treatments against COVID- $19^{7}$.

In this context, some important initiatives of the World Health Organisation are focused on the circulation of data and knowledge related to the pandemic and the instruments to fight against it, in particular the removal of national and legal barriers (e.g., Intellectual Property Rights) to 'facilitate open sharing of knowledge, intellectual property and data necessary for COVID-19 detection, prevention, treatment and response ${ }^{8}$.

The Rome Declaration itself confirms the 'commitment to global solidarity, equity, and multilateral cooperation; to effective governance; to put people at the centre of preparedness and equip them to respond effectively' (see the preamble; see also Principle no. 15 of the Rome Declaration).

\section{Conclusions}

Principle no. 7 of the Rome Declaration (see also Principle no. 10) is aimed at setting up a global system for the sharing of data, biological material, knowledge and technologies that are necessary to protect the health of the whole of humanity from threats such as the COVID-19 pandemic.

In order to achieve such an important objective, the previous paragraphs show that an adequate legal context must be built. This not only means the elaboration of new legal sources, in particular,

\footnotetext{
${ }^{7}$ WHO, The Access to COVID-19 Tools (ACT) accelerator. https://www.who.int/initiatives/act-accelerator.

${ }^{8} \mathrm{See}$, for example, https://www.who.int/initiatives/covid-19-technology-access-pool/solidarity-call-to-action and other documents of the WHO available at www.who.int.
} 
at the international level but also an interpretative approach which avoids the traditional view based on the proprietary paradigm and is grounded on the protection of human rights and the principle of (transnational) solidarity. Indeed, the new paradigm should be that of 'digital solidarity' as it is called by the European Data Protection Supervisor (EDPS) ${ }^{9}$. Digital solidarity 'should make data working for all people in Europe and especially for those the most vulnerable'.

On the other hand, EDPS underlines that 'Digital solidarity would refuse to replicate the now tarnished and discredited business models of constant surveillance and targeting that have so damaged trust in the digital society but will allow data protection serve mankind during this extraordinary exam in our knowledge, skills and our human values'. As matter of fact, the EU and international bodies stress that the sharing of data, even in an emergency, has to respect individual rights and other interests, such as privacy and security.

The Organisation for Economic Co-operation and Development in its 'Policy Responses to Coronavirus ${ }^{10}$ recommends that policymakers collaborate with privacy enforcement authorities to ensure that any extraordinary measures are proportionate to the risks and are implemented with full transparency and accountability along with a commitment to stop and update those measures when the situation changes.

The Council of Europe in its 'Recommendations on Privacy and Data Protection in the Fight against COVID-19' ${ }^{11}$ recalls that 'International and national laws recognize that extraordinary circumstances require extraordinary measures. This means that certain fundamental rights, including the rights to privacy and data protection, may be restricted to address the current health crisis as long as basic democratic principles and a series of safeguards are applied, and the interference is lawful, limited in time, and not arbitrary'.

Those measures have to comply with the principles foreseen in the European system of protection of human rights, that is, 'processing of personal data is carried out only if necessary and proportionate to the explicit, specified and legitimate purpose pursued; an impact assessment is carried out before the processing is started; privacy by design is ensured and appropriate measures are adopted to protect the security of data, in particular when related to special categories of data such as health related data; data subjects are entitled to exercise their rights' ${ }^{12}$.

The EU institutions and bodies have adopted several documents to apply the principles of the GDPR to the health emergency ${ }^{13}$ (such as minimisation and security, see Article 5 GDPR) [30]. However, the

\footnotetext{
${ }^{9}$ See the statement of the European Data Protection Supervisor, Wojciech Wiewiórowski, EU Digital Solidarity: A call for a pan-European approach against the pandemic of 6 April 2020.

${ }^{10}$ OECD Policy Responses to Coronavirus (COVID-19), Ensuring data privacy as we battle COVID-19, Version of 14 April 2020. http://www.oecd.org/coronavirus/policy-responses/ensuring-data-privacy-as-we-battle-covid-19-36c2f31e/ \#section-d1e690.

${ }^{11}$ https://www.accessnow.org/cms/assets/uploads/2020/03/Access-Now-recommendations-on-Covid-and-data-protectionand-privacy.pdf.

${ }^{12}$ See the joint statement of 30 March 2020 on the right to data protection in the context of the COVID-19 pandemic, at https://rm.coe.int/covid19-joint-statement/16809e09f4.

${ }^{13}$ Among the others: statement on the processing of personal data in the context of the COVID-19 outbreak. Adopted on 19 March 2020. https://edpb.europa.eu/sites/edpb/files/files/news/edpb_statement_2020_processingpersonaldataandcovid-19_ en.pdf; guidelines 04/2020 on the use of location data and contact tracing tools in the context of the COVID-19 outbreak. Adopted on 21 April 2020. https://edpb.europa.eu/sites/edpb/files/files/file1/edpb_guidelines_20200420_contact_tracing_covid_with_ annex_en.pdf; guidelines $03 / 2020$ on the processing of data concerning health for the purpose of scientific research in the context of the COVID-19 outbreak. Adopted on 21 April 2020, https://edpb.europa.eu/sites/edpb/files/files/file1/edpb_ guidelines_202003_healthdatascientificresearchcovid19_en.pdf; statement on restrictions on data subject rights in connection
} 
convergence towards common principles by the European bodies is not sufficient to provide a response to global problems such as the COVID-19 pandemic.

In order to implement an effective system for the exchange of data and for 'developing, enhancing and improving inter-operable early warning information, surveillance, and trigger systems in line with the One Health approach ... including rapid and transparent cross-sectoral and international information and data sharing' (see Principle 11 of the Declaration of Rome), a true global governance of health data and materials is needed, using all instruments which will be able to regulate the transnational relationships, including an extensive use of the modern forms of soft law [31].

\section{Acknowledgements}

This paper is a result of the activities carried out within the following projects: 'Umbria Biobank', PRJ1506, Azione 2.3.1, POR-FESR 2014-2020 (Italy), co-funded by the European Union and the Umbria Region; Jean Monnet Chair 'EU*5thFreedom', funded by the EACEA of the European Union in the Erasmus+ Programme.

\section{Conflict of interest}

None to report.

\section{References}

[1] Taylor M. Genetic Data and the Law: A Critical Perspective on Privacy Protection. Cambridge, 2012. p. 56.

[2] Perry M. Accessing accessions, biobanks and benefit-sharing Biobanks. In: Pascuzzi G, Izzo U, Macilotti M (eds) New York, NY: Springer; 2013. p. 267.

[3] Cippitani R. Consent to the use of genetic information: Between respect of privacy and protection of other fundamental interests Diritto e Processo/Right and Remedies/Derecho y Proceso 2014. pp. 493-532.

[4] Conforti B. Diritto Internazionale. Napoli, 2010. p. 3 ff.

[5] Henkin L. How Nations Behave. New York, 1979.

[6] de Witte J, Have H. Ownership of genetic material and information. Soc Sci Med. 1997;45(1):51-60.

[7] Pacheco Cornejo H. Conocimientos tradicionales Diccionario Analítico de Derechos Humanos e Integración Jurídica. In: Álvarez Ledesma MI, Cippitani R (eds)p. $67 \mathrm{ff}$.

[8] Rentier B. Open Science, the Challenge of Transparency. Bruxelles: Académie royale de Belgique; 2019.

[9] Chesbrough H. From Open Science to Open Innovation. Science|Business; 2015.

[10] KA. The European research area (ERA): science, knowledge, research \& innovation. Towards Europe 2020 Società della Conoscenza e Cultura dell'Integrazione. In: Cippitani R (ed) Roma-Perugia: ISEG; 2012. pp. 475-506.

[11] Cippitani R. Academic freedom as a fundamental right Paper presented at the 1st International Conference on Higher Education Advances, HEAd'15. Universitat Politécnica de Valéncia; 2015.

[12] Rodotà S. Il terribile diritto. Studi sulla proprietà privata. Bologna, 1990.

[13] Cippitani R. El Derecho de la Sociedad del Conocimiento. Rome: ISEG; 2012.

[14] Rifkin J. The Age of Access. Tarcher/Putnam; 2000.

[15] Ferrajoli L. Más allá de la soberanía y la ciudadanía: un constitucionalismo global Estado constitucional y globalización. In: Carbonell M, Vázquez R (eds) México, 2001. pp. 313-318.

to the state of emergency1 in Member States, adopted on 2 June 2020. https://edpb.europa.eu/sites/edpb/files/files/file1/edpb_ statement_art_23gdpr_20200602_en.pdf. 
[16] Rawls J. A Theory of Justice. Cambridge, MA, 1980. pp. 4-7.

[17] Palazzo A. Cittadinanza, ambiente e costituzione dei beni comuni. Diritto e processo; 2012. p. $217 \mathrm{ff}$.

[18] Cippitani R. La solidarietà giuridica tra pubblico e privato. Roma-Perugia; 2010.

[19] Peces-Barba Martinez G et al. Historia de los Derechos fundamentales, t. II, Siglo XVII, vol. I, El contexto social y cultural de los derechos. Los rasgos generales de evolución. Madrid, 2001.

[20] Rodotà S. La vita e le regole. Tra diritto e non diritto. Milano, Feltrinelli, 2006.

[21] Peces-Barba Martinez G. Derecho y derechos fundamentales. Madrid, 1993. p. 315.

[22] Bosco G. Lezioni di diritto internazionale. Milano, 1992. p. 587.

[23] Cippitani R. Solidaridad institucional en la Unión europea y crisis sanitaria Hacia la creación de un nuevo orden internacional pospandemia. El rol de los distintos procesos de integración en Europa y América Latina. In: Molina del Pozo CF (ed) Madrid: Centro De Estudios Financieros; 2021. pp. 47-71.

[24] Zobel K. Judge Alejandro Álvarez at the International Court of Justice (1946, 1955): His Theory of a 'New International Law' and Judicial Lawmaking. Leiden Journal of International Law. 2006;19:1020.

[25] Simma B. From Bilateralism to Community Interest in International Law Vol. 250, Recueil des Cours; 1994. pp. $217-384$.

[26] Riphagen W. Third Report on the Content, Forms and Degrees of International ResponsibilityYearbook of International Law Commission Vol. 2, part. 1 1982. pp. 22-50.

[27] Macdonald R St J. Solidarity in the practice and discourse of public international law. Pace International Law Review. 1996;8(2):259-302, Brunkhorst H. Solidarity. From Civic Friendship to a Global Legal Community. Cambridge/London: MIT Press; 2005

[28] Brizioli S. La dimensione internazionale della solidarietà pubblica Revista Institucional de la Defensa Pública de la Ciudad Autónoma de Buenos Aires, special issue 'Solidaridad pública y protección de los DDHH un diálogo entre Argentina e Italia' 2021. pp. 79-99.

[29] De Campos TC. Guiding principles of global health governance in times of pandemics: Solidarity, subsidiary, and stewardship in COVID-19. The America Journal of Bioethics. 2020;20(7):212-14.

[30] Kędzior M. The right to data protection and the COVID-19 pandemic: The European approach ERA Forum 2020. pp. $1-11$.

[31] Schneider L. State consent in international law-an obstacle to effective international problem-solving? Unter Gleichen, APARIUZ XXII, Sui generis. In: Hussmann L, Nickerson N, Sang Bastian A, Wujohktsang Y (eds) 2021. pp. 197-210. 